\title{
A cross-sectional study regarding the knowledge, attitude and awareness about self-medication among Bangladeshi people
}

Md. Abu Bakar Siddique Jami ( $\sim$ jamiu.cooper@yahoo.com )

\section{Research}

Keywords: Self-medication, Health, Drug, Medicine, Bangladesh, Prescription, Practice

Posted Date: September 28th, 2021

DOl: https://doi.org/10.21203/rs.3.rs-936639/v1

License: (a) (i) This work is licensed under a Creative Commons Attribution 4.0 International License.

Read Full License 


\section{Abstract}

Background: Self-medication is the use of medicinal products by the consumer which is not prescribed by the physician or doctor. Self-medication practice (SMP) is widely adopted by the common people of developing countries like Bangladesh.

Study Design: Cross-sectional study.

Aim \& Objective: This study was conducted to learn about the knowledge and awareness level and to evaluate the practice and attitude towards self-medication among the common people of Bangladesh.

Method: Primary data was collected by conducting an online survey with a well-constructed questionnaire. Data collection was carried out from May 2021 to June 2021. The subjects were minimum 15 years of age. From 35 districts of Bangladesh, total 322 people of different age groups, education levels, economic classes participated in the survey.

Result: $71 \%$ (229) of the respondents were $21-25$ years of age. $66 \%$ were undergraduate students. Most of them were from middle class society and well-educated. $80 \%$ of the population said that they had purchased or taken medicines without any prescription. $57 \%$ of them told they do not consider selfmedication as a very safe practice although, $87 \%$ of the population had practiced self-medication at least once in the preceding year. Antipyretics (212), Analgesics (165), Drugs for Cold/Cough (197) and Antiulcer/Antacids (140) were the majority categories of medicines that were used mostly for self-medication. Nearly all (311) of them collects SMP medicine from Pharmacy shops. Previous prescription (146), Advice from family or friends (165) and Internet or other media (113) were their common sources of information for their self-medication practice.

Conclusion: Self-medication practice is highly prevalent in Bangladesh. People are not aware enough about possible negative outcomes of it. Therefore, the regulatory laws should be implemented more strictly regarding buying and selling medicines

\section{Introduction}

\subsection{Definition \& Overview}

From some of the earliest histories of humans, there were evidences found of self- medication practice. Such as, proves were found that Neanderthal humans suffering from dental abscess practiced selfmedication [1]. Self-medication is being practiced every day in the form of self-care of our health throughout the globe [2]. According to the WHO guidelines, Self-medication can be identified as the use of drugs or medicinal substances by a Patient on his own or on the advice of a Pharmacist or any other lay person instead of consulting with a certified physician or doctor [3]. Previously done researches on selfmedication tell that it is a rather common practice, especially in economically deprived societies. Moreover, it is a growing trend of 'self-care' which has its own pros and cons. 
However, since it involves using drugs, self-medication can differ from self-care sometimes. And that may do good or can cause harm also. From the perspective of the people who practice it, self-medication provides them a low-cost alternative for consulting a general physician or doctor. Sometimes it genuinely helps to overcome or treat minor health conditions. For any minor illnesses or symptoms, sometimes it can be a cheap, rapid, and convenient solution [4], [5]. Therefore, Self-medication is the use of medicinal products or drug substances by the consumer which is not prescribed by the certified physician or doctor. It indicates selection, purchase and use of medicines by individuals to treat self-recognized health conditions, diseases or symptoms.

\subsection{Reasons \& Factors Influencing Self-Medication}

The major and most possible reason of self-medication practice is that; it saves a lot of time. Going to a specialized doctor or physician must takes a lot of times. It was revealed by a study that, $67 \%$ which is more than 35.5 million people of Britain do not book a face-to-face doctor's consultation even when it was required. Moreover, they consider visiting a doctor is a waste of time [6]. People often just selfmedicate themselves when they are suffering from a simple illness such as, fever, common cold, acidity, abdominal pain, cough, headache, back pain etc. A throat symptom like, sore throat or voice break, simple teeth or gum symptoms, symptoms related to minor respiratory problems etc. [7] were found as some of the main reasons for self- medication in Europe.

Previous studies show that, dissatisfaction with the healthcare services or doctor's behavior, being fed up about the lengthy waiting times as the doctors are mostly busy with many patients or having low amount of trust in the services of a doctor can also instigate the tendency of self-medication [8]. In least developed or developing countries, self-diagnosis of a disease and use of previously taken medicine for treatment without any prescription of a doctor is a highly common practice. However, a student of medicine or someone having proper academic knowledge about drugs and diseases might feel confident while taking a medicine based on their own understandings [8], [9]. According to several recent studies, the rate of self-medication practice appears to be increasing in Bangladesh. Due to a number of socioeconomic and lifestyle factors that include ready access to drugs, increased potential to manage certain illnesses through self- care, and greater availability of medicinal products, people are choosing this over going to the doctors.

It is also a quite common scene that, pharmacist or the person who sells the medicine in a drugstore influences the patient to purchase and take a particular drug just by hearing the symptoms [8]. Along with these reasons or factors, having old medicines left at home, other people's suggestions and many other possible reasons can be there that can invoke someone to practice self-medication without visiting a doctor.

\section{Materials \& Methods \\ 2.1 Type of Study}


This study is a cross-sectional study. It is designed to find out the knowledge, awareness of people about self-medication and to evaluate behavior and practice of the common people from different regions of Bangladesh.

\subsection{Study Area}

The survey for this study was conducted on the general and common people from different districts or distinct regions of Bangladesh. People from different parts of the country participated in this study.

\subsection{Sample Characteristics}

For this study, primary data was collected by conducting an online survey with a well-constructed questionnaire form. These data were both quantitative and qualitative. Since, this survey is being conducted in the Covid-19 pandemic period, people are more engaged with online activities and so it seemed most convenient method to collect data online. Data collection was carried out from May 2021 to June 2021. A total of 322 people participated in the survey from people of different age groups \& education levels.

\subsubsection{Inclusion Criteria}

Subjects must be from any district or any region of Bangladesh. must have a minimum knowledge of digital technology and should be able to fill-up the online questionnaire. The participant has their consent regrading using their opinions in the questionnaire.

\subsubsection{Exclusion Criteria}

Those who were not willing to participate in this particular study are excluded from the study. Those who were under minimum 15 years of age were also excluded. To maintain the uniformity of the data, people who are not from any part of Bangladesh were avoided.

\subsection{Sampling Technique}

In this study, stratified random sampling technique was followed. The sample was collected from both male and female. People of different age groups, education levels, economic classes and ethnic background were selected for the survey.

\subsection{Questionnaire Development}

The questionnaire is constructed in both English and Bengali. They were written in simple language in order to avoid unnecessary semantic misunderstandings. All the questions were analyzed well for relevance with the study, before making the final forms by taking help from experts. Some specific questions had the option of choosing multiple answers and some had extra spaces for comments and additional information.

\subsection{Data Collection Method}


Data were collected online through google form predominantly. Some responses were also taken by faceto-face interviews or through phone calls, for those participants who do not have email address, no access to the internet, and poor understanding of technology.

\subsection{Data Analysis}

After data collection, they were checked and analyzed with Microsoft Excel 2016. Here, help from an expert statistician was also taken. Results were shown in tables, pie and column diagrams. After scrutinizing the results, conclusive numbers and percentages were found regarding the knowledge and attitude of people regarding self-medication.

\section{Results \& Discussion}


Table 1

Demographic Characteristics.

\begin{tabular}{|c|c|c|}
\hline Characteristics & Frequency (n) & Percentage (\%) \\
\hline \multicolumn{3}{|l|}{ Age group (years) } \\
\hline $15-20$ & 34 & 10.56 \\
\hline $21-25$ & 229 & 71.12 \\
\hline $26-30$ & 29 & 9.01 \\
\hline $31-40$ & 12 & 3.73 \\
\hline$>40$ & 18 & 5.59 \\
\hline \multicolumn{3}{|l|}{ Gender } \\
\hline Male & 197 & 4.05 \\
\hline Female & 125 & 27.02 \\
\hline \multicolumn{3}{|l|}{ Socio-economic status } \\
\hline Upper class & 8 & 2.48 \\
\hline Upper middle class & 59 & 18.32 \\
\hline Middle class & 216 & 67.08 \\
\hline Lower middle class & 38 & 11.80 \\
\hline Lower class & 1 & 0.31 \\
\hline \multicolumn{3}{|l|}{ Educational status } \\
\hline Secondary & 21 & 6.52 \\
\hline Higher Secondary & 28 & 8.70 \\
\hline Undergraduate (ongoing) & 211 & 65.53 \\
\hline Graduation & 36 & 11.18 \\
\hline Post-Graduation & 26 & 8.07 \\
\hline \multicolumn{3}{|l|}{ Field of Study } \\
\hline Science & 215 & 66.77 \\
\hline Business & 55 & 17.08 \\
\hline Arts & 42 & 13.04 \\
\hline Madrassa & 2 & 0.62 \\
\hline Other & 8 & 2.48 \\
\hline
\end{tabular}




\begin{tabular}{|lll|}
\hline Characteristics & Frequency $(\mathbf{n})$ & Percentage (\%) \\
\hline Current Residence & & \\
\hline City or urban area & 251 & 77.95 \\
\hline Suburban area & 46 & 14.29 \\
\hline Village or rural area & 25 & 7.76 \\
\hline
\end{tabular}

Table 2: Knowledge and Behavior on Self-medication. 
Table 2

Knowledge and Behavior on Self-medication.

\begin{tabular}{|c|c|c|}
\hline Characteristics & Frequency (n) & Percentage (\%) \\
\hline \multicolumn{3}{|l|}{ Age group (years) } \\
\hline $15-20$ & 34 & 10.56 \\
\hline $21-25$ & 229 & 71.12 \\
\hline $26-30$ & 29 & 9.01 \\
\hline $31-40$ & 12 & 3.73 \\
\hline$>40$ & 18 & 5.59 \\
\hline \multicolumn{3}{|l|}{ Gender } \\
\hline Male & 197 & 4.05 \\
\hline Female & 125 & 27.02 \\
\hline \multicolumn{3}{|l|}{ Socio-economic status } \\
\hline Upper class & 8 & 2.48 \\
\hline Upper middle class & 59 & 18.32 \\
\hline Middle class & 216 & 67.08 \\
\hline Lower middle class & 38 & 11.80 \\
\hline Lower class & 1 & 0.31 \\
\hline \multicolumn{3}{|l|}{ Educational status } \\
\hline Secondary & 21 & 6.52 \\
\hline Higher Secondary & 28 & 8.70 \\
\hline Undergraduate (ongoing) & 211 & 65.53 \\
\hline Graduation & 36 & 11.18 \\
\hline Post-Graduation & 26 & 8.07 \\
\hline \multicolumn{3}{|l|}{ Field of Study } \\
\hline Science & 215 & 66.77 \\
\hline Business & 55 & 17.08 \\
\hline Arts & 42 & 13.04 \\
\hline Madrassa & 2 & 0.62 \\
\hline Other & 8 & 2.48 \\
\hline
\end{tabular}




\begin{tabular}{|lll|}
\hline Characteristics & Frequency (n) & Percentage (\%) \\
\hline Current Residence & & \\
\hline City or urban area & 251 & 77.95 \\
\hline Suburban area & 46 & 14.29 \\
\hline Village or rural area & 25 & 7.76 \\
\hline
\end{tabular}




\begin{tabular}{|c|c|c|}
\hline Characteristics & Frequency (n) & Percentage (\%) \\
\hline \multicolumn{3}{|c|}{ What do the participants do most of the times when they feel any physical discomfort } \\
\hline Do nothing & 51 & 15.84 \\
\hline See the doctors & 87 & 27.02 \\
\hline Seek help from family or friends & 79 & 24.53 \\
\hline Take medicines by yourself & 105 & 32.61 \\
\hline \multicolumn{3}{|c|}{ Being aware of the term 'self-medication' before this survey } \\
\hline Yes & 203 & 63.04 \\
\hline No & 107 & 33.23 \\
\hline Prefer not to answer & 12 & 3.73 \\
\hline \multicolumn{3}{|c|}{ Ever purchased or took medicines without any prescription } \\
\hline Yes & 259 & 80.43 \\
\hline No & 54 & 16.77 \\
\hline Prefer not to answer & 9 & 2.80 \\
\hline \multicolumn{3}{|c|}{ Reason for self-medication ( ${ }^{*}$ can be multiple reasons) } \\
\hline Characteristics & \multicolumn{2}{|c|}{ Frequency $(n)$} \\
\hline Saves time & \multicolumn{2}{|l|}{138} \\
\hline I have old prescription & \multicolumn{2}{|l|}{116} \\
\hline I have medicines of family members & \multicolumn{2}{|l|}{72} \\
\hline Pharmacist or medicine store seller's advice & \multicolumn{2}{|l|}{154} \\
\hline Doctor / clinic far from home & \multicolumn{2}{|l|}{26} \\
\hline High fees of doctors & \multicolumn{2}{|l|}{92} \\
\hline Doctors are very busy with many patients & \multicolumn{2}{|l|}{41} \\
\hline Do not have enough trust in doctors & \multicolumn{2}{|l|}{22} \\
\hline Other & \multicolumn{2}{|l|}{28} \\
\hline \multicolumn{3}{|c|}{ History of self-medication practice (in preceding one year) } \\
\hline Characteristics & Frequency (n) & Percentage (\%) \\
\hline $1-2$ times & 104 & 32.30 \\
\hline $3-4$ times & 84 & 26.09 \\
\hline
\end{tabular}




\begin{tabular}{|c|c|c|}
\hline Characteristics & Frequency (n) & Percentage (\%) \\
\hline $4-5$ times & 21 & 6.52 \\
\hline $5-6$ times & 19 & 5.90 \\
\hline 7 or more times & 52 & 16.15 \\
\hline Never & 42 & 13.04 \\
\hline \multicolumn{3}{|c|}{ Considerations behind choosing a medicine for self-medication ( ${ }^{*}$ can be multiple reasons) } \\
\hline Characteristics & \multicolumn{2}{|c|}{ Frequency (n) } \\
\hline Price & \multicolumn{2}{|l|}{30} \\
\hline Pharmaceutical Company & \multicolumn{2}{|l|}{164} \\
\hline Type of medicine & \multicolumn{2}{|l|}{157} \\
\hline Brand & \multicolumn{2}{|l|}{106} \\
\hline Someone's suggestion & \multicolumn{2}{|l|}{114} \\
\hline Other & \multicolumn{2}{|l|}{14} \\
\hline \multicolumn{3}{|c|}{ Place or medium of acquiring medicine for self-medication (*can be multiple reasons) } \\
\hline Characteristics & \multicolumn{2}{|c|}{ Frequency (n) } \\
\hline Pharmacy shop & \multicolumn{2}{|l|}{311} \\
\hline Online shopping & \multicolumn{2}{|l|}{8} \\
\hline Medicines of family members or friends & \multicolumn{2}{|l|}{57} \\
\hline Primary health care center & \multicolumn{2}{|l|}{10} \\
\hline Medical representatives & \multicolumn{2}{|l|}{12} \\
\hline Others & \multicolumn{2}{|l|}{4} \\
\hline \multicolumn{3}{|c|}{ Checking the prescribing information before self-medicating } \\
\hline Characteristics & Frequency (n) & Percentage (\%) \\
\hline Yes, always & 151 & 46.89 \\
\hline Yes, sometimes & 139 & 43.17 \\
\hline No, never & 32 & 9.94 \\
\hline \multicolumn{3}{|c|}{ Level of understanding the instructions of prescribing information paper } \\
\hline Fully understand & 121 & 37.58 \\
\hline Partially understand & 177 & 54.97 \\
\hline
\end{tabular}




\begin{tabular}{|c|c|c|}
\hline Characteristics & Frequency (n) & Percentage (\%) \\
\hline Not at all & 24 & 7.45 \\
\hline \multicolumn{3}{|l|}{ Awareness of the term 'drug-drug interaction' } \\
\hline Yes & 154 & 47.83 \\
\hline No & 168 & 52.17 \\
\hline \multicolumn{3}{|l|}{ Awareness of the term 'drug-food interaction' } \\
\hline Yes & 151 & 46.89 \\
\hline No & 171 & 53.11 \\
\hline \multicolumn{3}{|c|}{ Knowledge about potential adverse drug reactions from self-medication } \\
\hline Yes & 81 & 25.16 \\
\hline No & 55 & 17.08 \\
\hline About some medicines & 186 & 57.76 \\
\hline \multicolumn{3}{|c|}{ Source of information about the self-medicated medicine } \\
\hline Characteristics & \multicolumn{2}{|c|}{ Frequency (n) } \\
\hline Old prescription & \multicolumn{2}{|l|}{146} \\
\hline Advice from family or friends & \multicolumn{2}{|l|}{165} \\
\hline Advice from doctor but without prescription & \multicolumn{2}{|l|}{79} \\
\hline Internet or other media & \multicolumn{2}{|l|}{113} \\
\hline Other & \multicolumn{2}{|l|}{10} \\
\hline \multicolumn{3}{|c|}{ Experience of adverse effect after self-medication } \\
\hline Characteristics & Frequency (n) & Percentage (\%) \\
\hline Yes & 43 & 13.35 \\
\hline No & 279 & 86.65 \\
\hline \multicolumn{3}{|c|}{ Perspective about the safety of self-medication practice } \\
\hline Yes & 26 & 8.07 \\
\hline No & 184 & 57.14 \\
\hline Not sure & 112 & 34.78 \\
\hline \multicolumn{3}{|c|}{ Participation in social awareness activity regarding self-medication } \\
\hline Yes, I took part & 26 & 8.07 \\
\hline
\end{tabular}




\begin{tabular}{|lll|}
\hline Characteristics & Frequency (n) & Percentage (\%) \\
\hline No, never seen such things & 221 & 68.63 \\
\hline Have seen such things but never taken part & 75 & 23.29 \\
\hline Health insurance & & \\
\hline Government sponsored insurance & 5 & 1.55 \\
\hline Insurance provided by employers & 6 & 1.86 \\
\hline Private medical insurance & 7 & 2.17 \\
\hline Rural insurance & 3 & 0.93 \\
\hline No insurance & 301 & 93.48 \\
\hline
\end{tabular}

\section{(** Large table, shown at the end.)}

In this study it was tried to find out what is the attitude and behavior of the common people of Bangladesh regarding self-medication. While analyzing the tables and Figs, all the percentages found from results were rounded up for convenience of discussion. Firstly, the demographic condition of the participants was evaluated. Most of these people (55\%) are from Dhaka, the capital city of Bangladesh. People from 34 other districts of Bangladesh have also participated in it, but their numbers are not so high. Majority (229) of the respondents were young adults, from the age group of 21-25 years which was $71 \%$ of the total study population. Majority $(61 \%)$ of them were male and rest $39 \%$ were female, indicating that males tend to go out and shop or buy medicines more than the females. Then another demographic aspect is the socioeconomic status of the participants. Most of them (216) belong to the middle class category in the socioeconomic hierarchy. The percentage of this population was $67 \%$ among the total study population. When it comes to their educational status, $211(66 \%)$ out of the 322 participants were ongoing undergraduate, which was the majority. Moreover, the highest number of the participants were from Science study background and the second highest were the Business studies background. The percentages were $67 \%$ and $17 \%$ respectively. So, all of the study population were educated and majority of them were very well-educated actually. Also, majority of them are city dwellers. 251 (78\%) of them told they belong from urban areas. These were the demographic characteristics that were found after analyzing and studying the results.

Coming to the main part of this discussion which is, their knowledge, behavior and practice of selfmedication. Upon asking, what do the participants do most of the times, when they feel any physical discomfort, 105 (33\%) of the participants answered that they take medicines by themselves. Others mostly said that they seek help from family or friends or initially do nothing. Only $27 \%$ of them told that they see the doctors first.

While searching for medicines that are self-medicated mostly without prescription, there were more than 15 categories found. However, among all these types, Antipyretics (212), Analgesics (165), drugs for 
Cough/Cold (197) and Anti-ulcer/Antacids (140) were the majority categories of medicines that were used mostly for self-medication. Upon asking the participants, about their considerations behind choosing a medicine for self-medication (without prescription), the options Pharmaceutical Company (164), Type of medicine (157), Some- one's suggestion (114) and Brand (106) were almost equally chosen by the participants since, they had the option of choosing more than one answer for this question.

Nearly all of the participants (311 out of total 322) have told they collect their medicine directly from 'Pharmacy shop' or medicine store. Besides that, majority of the respondents claimed that they always $(47 \%)$ or sometimes $(43 \%)$ check the prescribing information or instructions. However, more than half of the population (55\%) told they understand those written instructions of the prescribing information partially while, $38 \%$ claimed to under- stand fully. Around half of the participants claimed to be aware of the terms 'drug-drug interaction' (52\%) and 'drug-food interaction' (53\%). More than half of the respondents $(55 \%)$ claimed that they knew about the possible adverse effects of some of the medicines they used for SMP but not all.

Other than these, as their source of information about the self-medicated medicine there were two to three options that were chosen by almost equal number of participants such as, Old prescription (146), Advice from family or friends (165) and Internet or other media (113). Majority (87\%) of the participants claimed that they never experienced any adverse effect after self-medication. More than half of the study population (57\%) had stated that, overall they do not consider self-medication as a very safe practice although, it was already seen that $87 \%$ of these people have practiced self-medication at least once in the last one year. So there is definitely some unwariness present among the majority of these people. Most of them (221 out of 322) said that they had never seen any social awareness program like seminar, discussion or even any online activity about the safety or practice of self-medication. Lastly, $93 \%$ of these participants had no health insurance at all, which is clearly indicating their lack of awareness and intent to invest for health issues.

\section{Conclusion}

Self-medication is quite highly prevalent in Bangladesh. Majority of the participants (80\%) had purchased or taken medicines without any prescription thus, knowingly or unknowingly practiced self-medication at least once or more in their life. The results give the idea that, not only the majority of people are taking SMP but many people who are practicing it claimed to be already informed about it. Majority people are from middle class society and they are quite well-educated. But still there are a persistent unawareness among them about self-medication. Despite having enough academic education, they are still nonchalant and careless about the gravity of the arising problems by this practice. They lack the minimum necessary amount of knowledge about health and medicine. Furthermore, $93 \%$ of these participants had no health insurance, clearly indicating their lack of awareness and intent to invest for their health issues and own good. 
Therefore, the regulatory laws should be implemented more strictly regarding buying and selling medicines. More social awareness programs like seminars, workshops etc. should be organized to make the healthcare providers, pharmacists and above all, the common people more aware about the proper way of taking the benefits from this practice and also the possible health risks from practicing selfmedication arbitrarily.

\section{Declarations}

\subsection{Ethical Approval \& Consent to Participate.}

The study was approved by the East West University Research Ethical Committee (EWUREC), and conducted in accordance with the Declaration of Helsinki. Survey participants were informed that the information collected would be kept anonymous and that their role in the study would be completely voluntary.

\subsection{Competing Interest}

The author declares that he has no competing interests.

\subsection{Consent for Publication}

Proper approval and was taken from the research supervisor and the Department of Pharmacy, East West University before submitting the manuscript for publication.

\subsection{Availability of Data and Materials}

The datasets generated during and/or analyzed during the study are available from the corresponding author on reasonable request.

\subsection{Funding Information}

This research received no specific grant from any funding agency, commercial or not-for-profit sectors.

\subsection{Authors' Contributions}


The corresponding author has designed the study, collected, analyzed, and interpreted the data and wrote the manuscript under the guidance and supervision of his university research supervisor.

\subsection{Acknowledgement}

I would like to express my humble gratitude and sincere thanks to my research supervisor, Kushal Biswas, Senior Lecturer, Department of Pharmacy, East West University, who has always given me his valuable guidance, advice and encouragement. My gratefulness to the Chairperson of the Department of Pharmacy, Dr. Chowdhury Faiz Hossain, who has always been a great inspiration for me. I also express my appreciation to all the teachers and staffs in the Department of Pharmacy, East West University.

\section{References}

[1] L. S. Weyrich et al., "Neanderthal behaviour, diet, and disease inferred from ancient DNA in dental calculus.," Nature, vol. 544, no. 7650, pp. 357-361, Apr. 2017, doi: 10.1038/nature21674.

[2] S. Kayalvizhi and R. Senapathi, "Evaluation of the Perception, attitude and knowledge about Selfmedication among business students in 3 select cities," Int. J. Enterp. Innov. Manag. Stud., vol. 1, no. 3, pp. 40-44, 2007, [Online]. Available:

https://pdfs.semanticscholar.org/84de/11896b245b6efbaf2cab70b39ed1ed96526e.pdf. (accessed Jul. $27,2021)$

[3] A. Sundararajan and A. K. Thangappan, "Knowledge, attitude and practice of self medication among undergraduate medical students in a teaching institution," Int. J. Basic Clin. Pharmacol., vol. 7, no. 12, p. 2414, 2018, doi: 10.18203/2319-2003.ijbcp20184857.

[4] D. Bennadi, "Self-medication: A current challenge," J. Basic Clin. Pharm., vol. 5, no. 1, p. 19, 2014, doi: 10.4103/0976-0105.128253.

[5] X. Lei, H. Jiang, C. Liu, A. Ferrier, and J. Mugavin, "Self-medication practice and associated factors among residents in Wuhan, China," Int. J. Environ. Res. Public Health, vol. 15, no. 1, 2018, doi: 10.3390/ijerph15010068. 
[6] Actuarial Post, "Millions delay seeing a doctor so as not to waste their time," 2020. https://www.actuarialpost.co.uk/article/millions-delay-seeing-a-doctor-so-as-not-to-waste-their-time19001.htm (accessed Jul. 28, 2021).

[7] L. Grigoryan et al., "Self-medication with antimicrobial drugs in Europe," Emerg. Infect. Dis., vol. 12, no. 3, pp. 452-459, 2006, doi: 10.3201/eid1203.050992.

[8] M. S. Moonajilin et al., "Prevalence and drivers of self-medication practices among savar residents in Bangladesh: A cross-sectional study," Risk Manag. Healthc. Policy, vol. 13, pp. 743-752, 2020, doi: 10.2147/RMHP.S256272.

[9] M. Hashemzaei, M. Afshari, Z. Koohkan, A. Bazi, R. Rezaee, and K. Tabrizian, "Knowledge, attitude, and practice of pharmacy and medical students regarding self-medication, a study in Zabol University of Medical Sciences; Sistan and Baluchestan province in south-east of Iran," BMC Med. Educ., vol. 21, no. 1, pp. 1-10, 2021, doi: 10.1186/s12909-020-02374-0.

[10] M. Khan, A. Ahmad, N. Khalique, M. A. Ansari, M. Maroof, and M. Najmul Aqib Khan, "Selfmedication practices in rural Aligarh, Uttar Pradesh, India," Int. J. Community Med. Public Heal., vol. 3, pp. 2874-2877, Sep. 2016, doi: 10.18203/2394-6040.ijcmph20163376.

\section{Appendix A}

\section{Survey Questionnaire: Self-medication: Knowledge, Awareness, Attitude and Practice}


Name:

Address:
Age?
a) $15-$
b) $20-24$
c) $25-29$
d) $30-34$
e) Other:

19

Gender?

a) Male

b) Female

c) Other

1. Your socio-economic status?
a) Upper
b) Upper middle
c) Middle class
d) Lower middle class
e) class class Other:

\section{Current educational status?}
a) Secondary
b) Higher Secondary
c) Undergraduate (ongoing)
d) Graduation
e) Post-Graduation
f) Other:

\section{What's your field of study?:}
a. Science
b. Arts
c. Business
d.
Others

\section{Your current residence?}
a) Rural area
b) Sub-urban area
c) City or urban area

5. When you feel any physical discomfort, what do you do most of the times?
a) See the doctors
b) Take medicines by yourself
c) Seek help from family or friends
d) Do nothing
e) Other:

\section{Are you aware of the term "self-medication"?}
a) Yes
b) No
c) Prefer not to answer

7. Did you ever purchase or take medicines without any prescription?
a) Yes
b) No
c) Prefer not to answer

8. If Yes, what are your reason of self-medication?
a) Doctor / clinic far from
b) Saves time
c) High fees of doctor home
d) I have old prescription
e) Doctor is busy with many patients
f) I have medicines of family members
g) No trust in doctor
I) Pharmacist advice
j) Other

9. Your history of self-medication practice (in last one year)? 

a) 1 - 2 times
b) 3 - 4 times
c) 4 - 5 times
d) 5 - 6 times
e) 7 or more times
f) Never

10. Which of the following drugs have you taken mostly without prescription? (*can select multiple choices)

\begin{tabular}{llll} 
Antibiotics & $\begin{array}{l}\text { Drugs for fever } \\
\text { (antipyretics) }\end{array}$ & Pain killers (analgesics) & $\begin{array}{l}\text { Antihistamines } \\
\text { (anti-allergy) }\end{array}$ \\
$\begin{array}{l}\text { For cough, cold } \\
\text { and sore throat }\end{array}$ & $\begin{array}{l}\text { Nutritional/energy } \\
\text { supplement/vitamins }\end{array}$ & $\begin{array}{l}\text { Anti-ulcer/Antacids (acidity } \\
\text { drugs) }\end{array}$ & $\begin{array}{l}\text { Drugs for } \\
\text { diarrhea }\end{array}$ \\
\hline $\begin{array}{l}\text { Drugs for } \\
\text { constipation }\end{array}$ & Insomnia (sedatives) & Oral contraceptives & $\begin{array}{l}\text { Anti-emetics } \\
\text { (anti-vomiting) }\end{array}$ \\
\hline $\begin{array}{l}\text { Nasal/Ear/Eye } \\
\text { drops }\end{array}$ & For skin diseases & Cuts, wounds and bruises & Others:
\end{tabular}

11. While choosing a self-medicated drug, what is your consideration?

( ${ }^{*}$ can select multiple choices)

Price

Pharmaceutical Company

Type of medicine

Brand

Someone's suggestion

Others

\section{Where do you purchase your self-medicated medication?}

( ${ }^{*}$ can select multiple choices)

Pharmacy shop Online shopping

Primary health care center

Medical representatives

Friends / family

Others

13. Do you check the prescribing information before self-medicating?
a) Yes,
always
b) Yes,
c) No, never
sometimes

14. How much did you understand from the instructions of prescribing information?
a) Fully understood
b) Partially understood
c) Not at all

\section{Are you aware of the term drug-drug interaction?}
a) Yes
c) No

16. Are you aware of the term drug-food interaction?
a) Yes
c) No

17. Do you know the potential adverse drug reactions of the drug by which you self-medicated without prescription?
a) Yes
b) About some drugs
c) No 
18. What's your source of information about your self-medicated medicine?

\section{(*can select multiple choices)}
a) Old
b) Advice from
c) Advice from doctor
d) Internet or other media
e)
prescription
family or friends
but without
Other:
prescription

19. Did you ever faced any kind of adverse effect after taking drug without prescription?
a) Yes
b) No

20. Overall, do you think self-medication practice is safe?
a) Yes
b) No
c) Not sure

21. Did you ever see or take part to any awareness program like seminar, discussion or even any online activity about self-medication?
a) Yes, I took part
b) Have seen such things but never
c) No, never seen such taken part things

22. What kind of health insurance do you have?
a) No insurance
b) Government sponsored insurance
c) Rural insurance
d) Private medical insurance
e) Insurance provided by Employers
f) Other

Figures

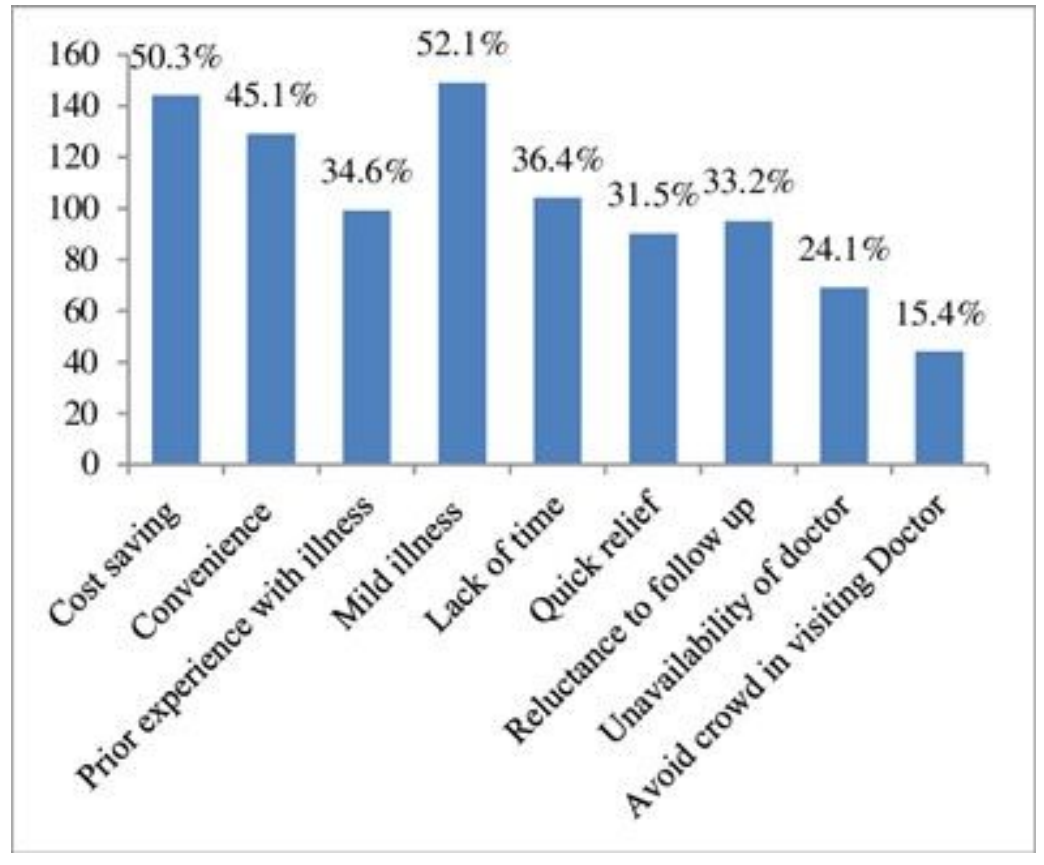


Figure 1

Reasons for self-medication (N=397) in a study at Aligarh, UP, India.

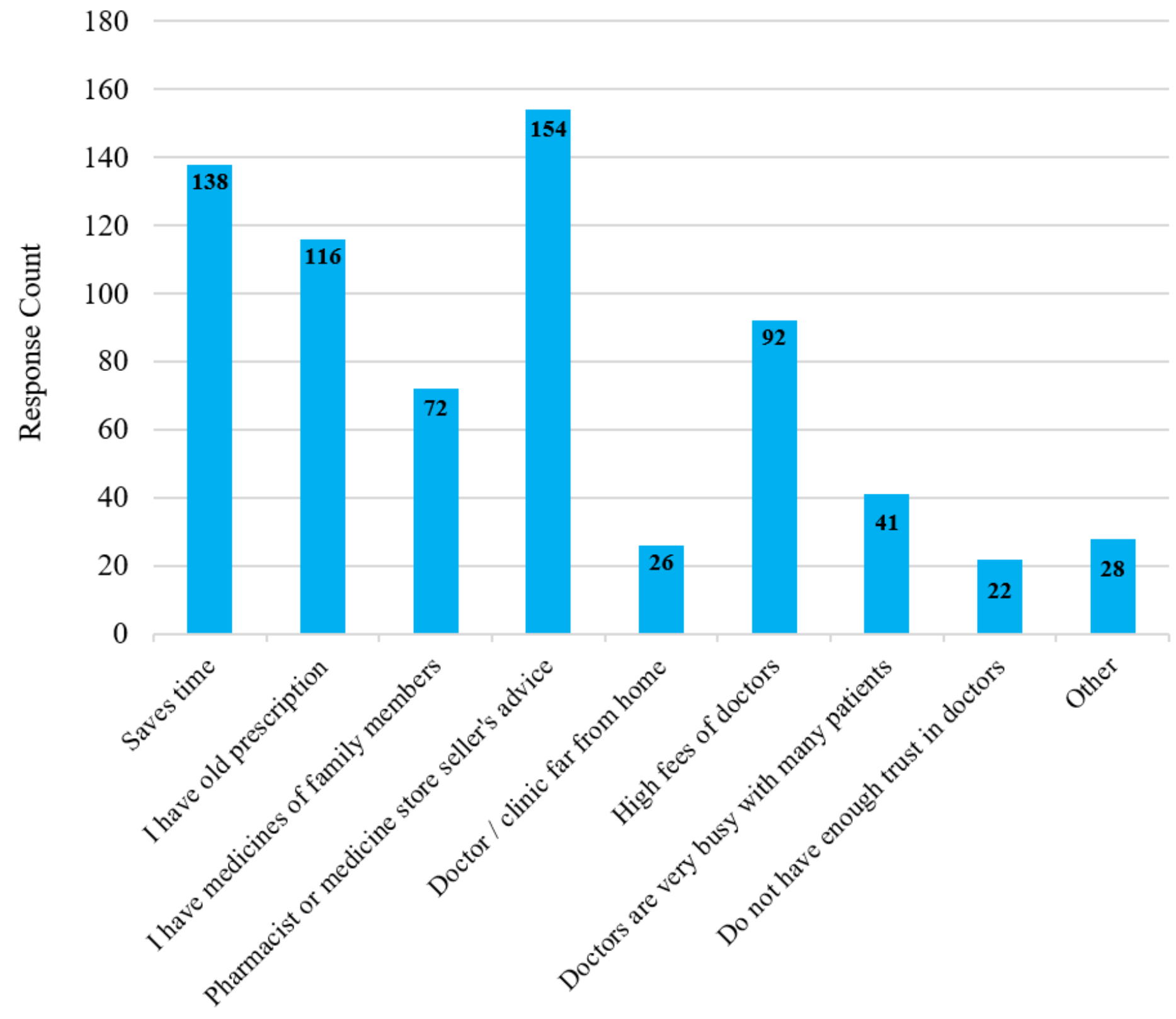

Figure 2

Distribution of total participants according to their reason for self-medication. 


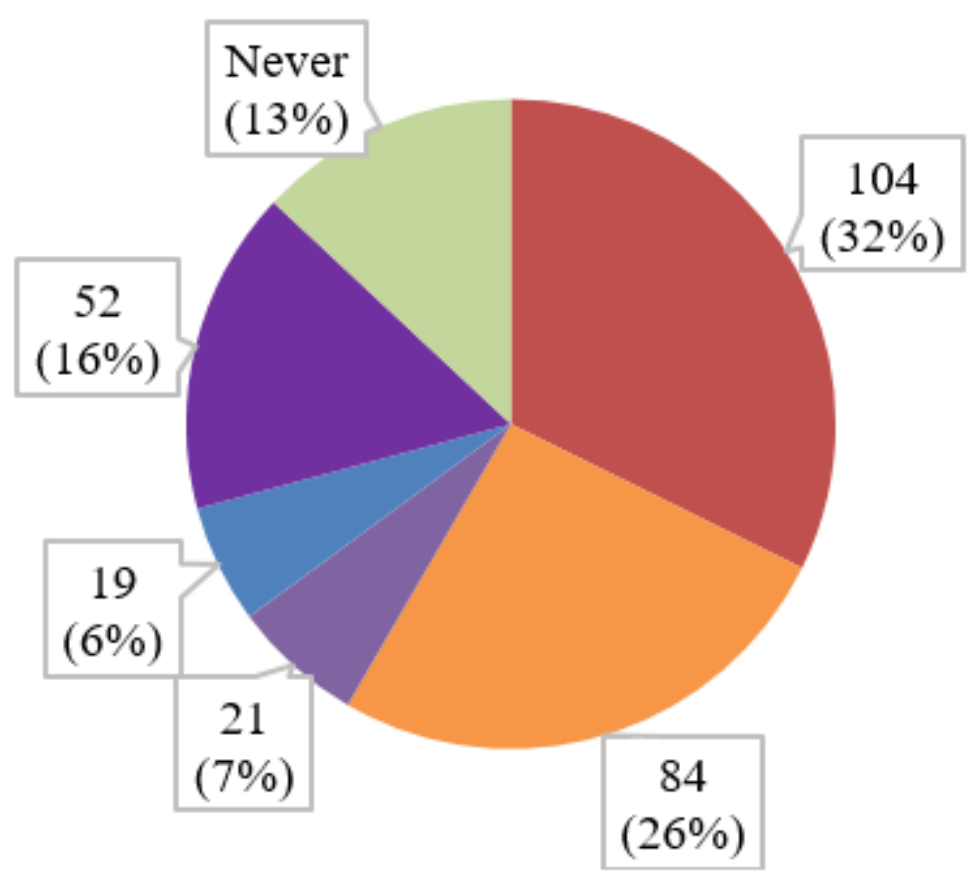

- 1-2 times

3-4 times

4-5 times

5-6 times

Figure 3

Distribution of total participants according to their history of self-medication practice.

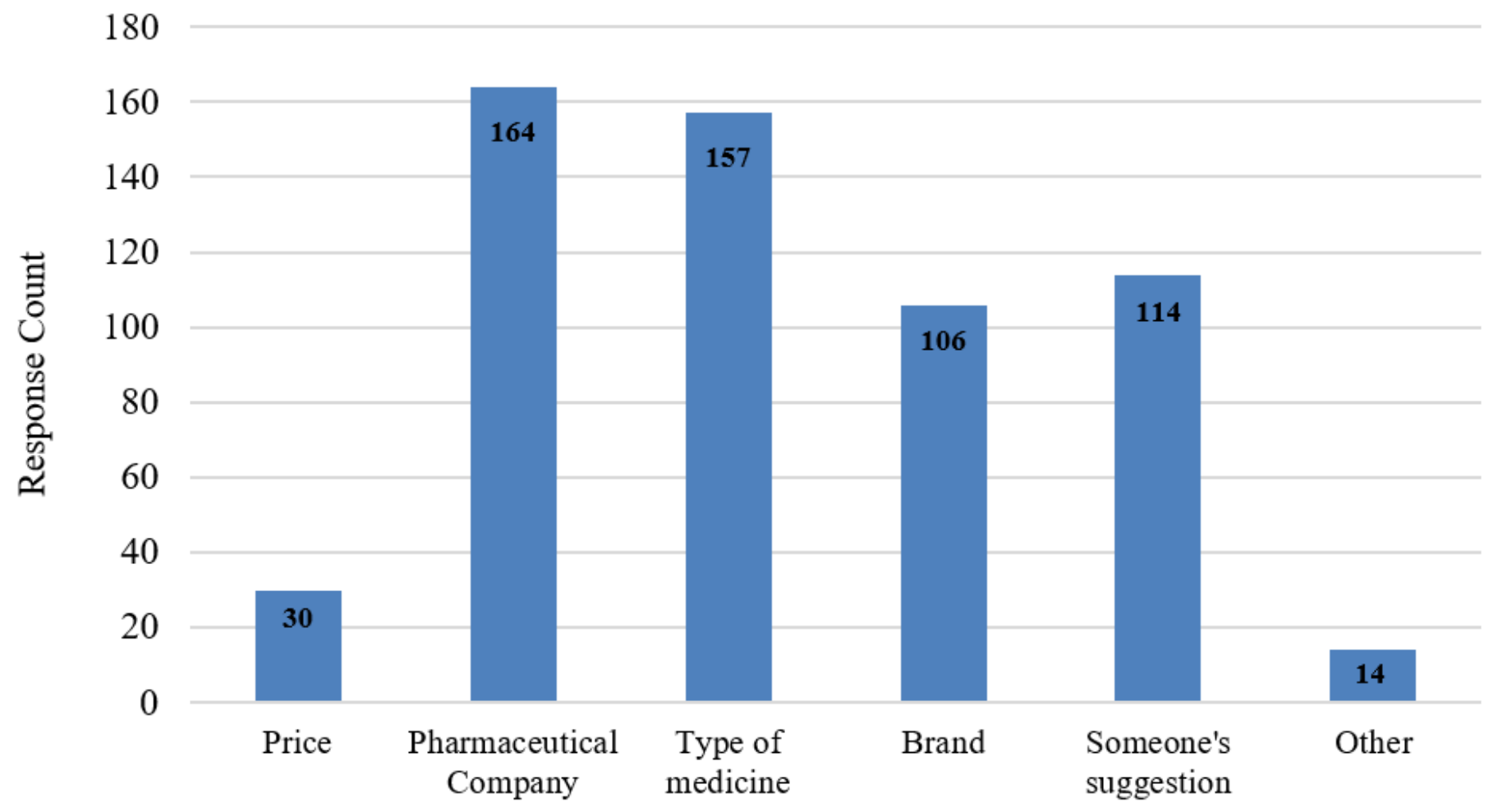

Figure 4 
Distribution of total participants according to their considerations behind choosing a medicine for selfmedication.

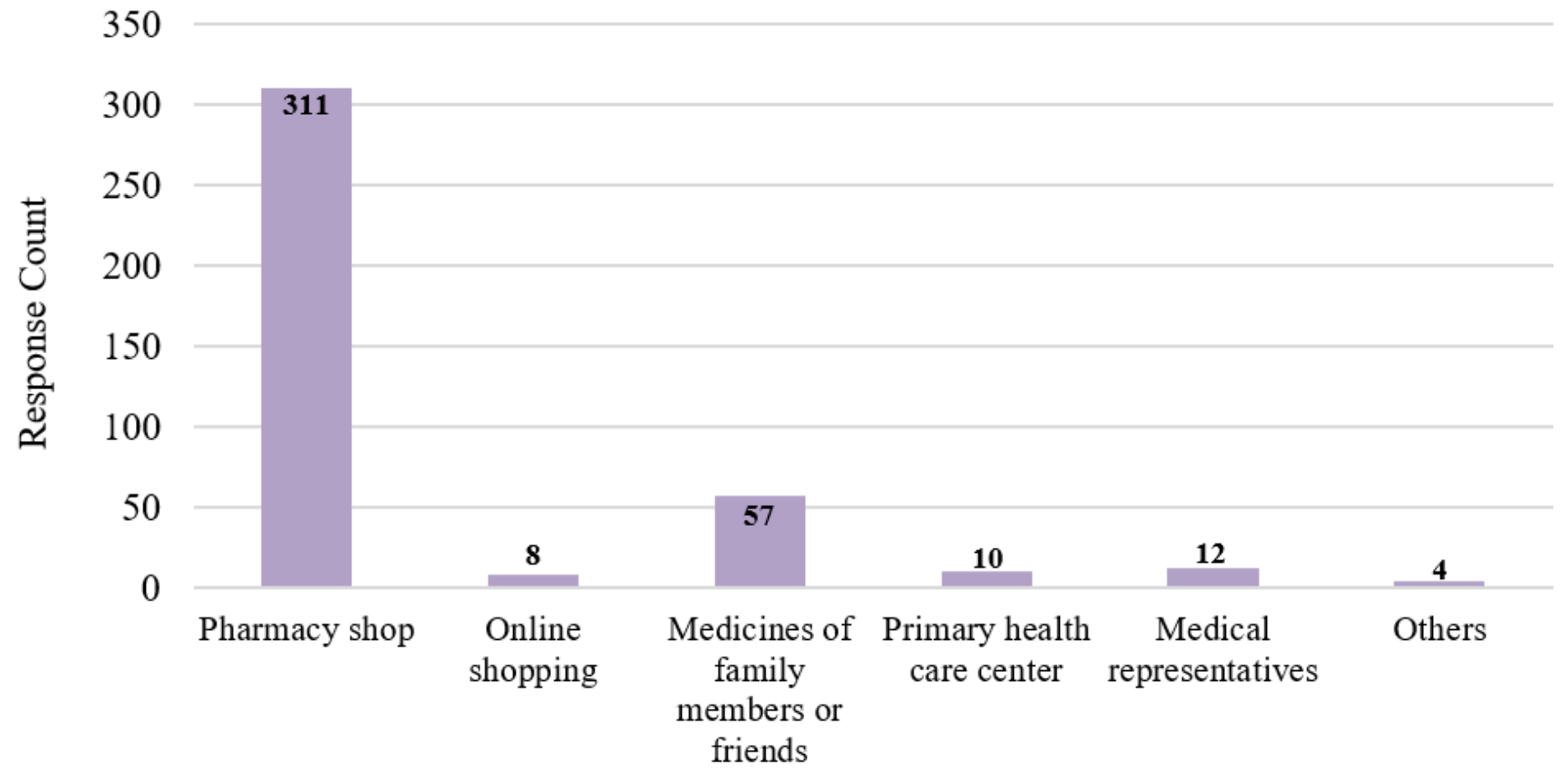

\section{Figure 5}

Distribution of total participants according to their choice of place or medium of acquiring medicine for self-medication. 
250

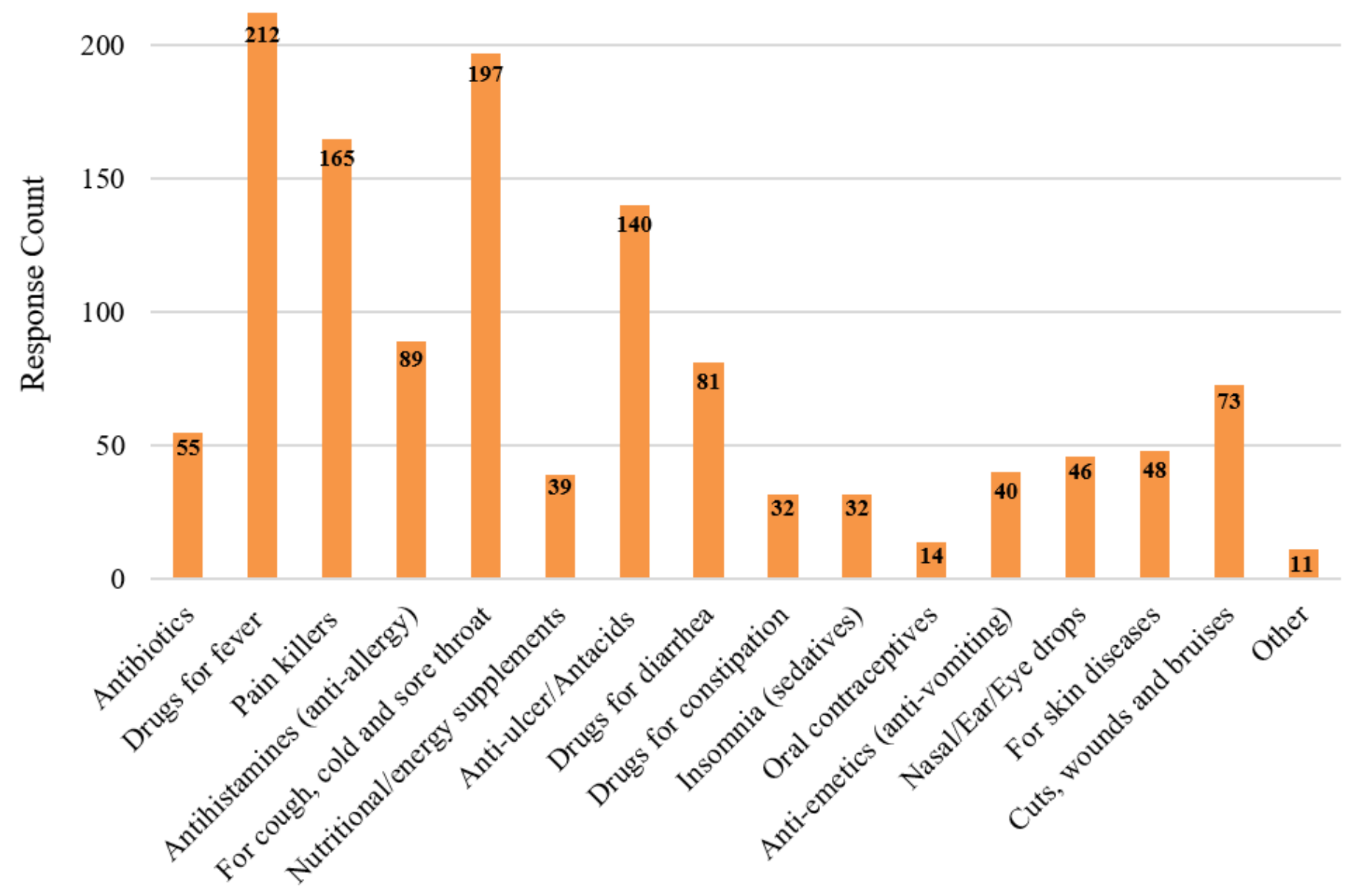

Figure 6

Distribution of total participants according to which medicines they self-medicated mostly without prescription. 